\title{
Perilaku Hidup Bersih dan Sehat Sebagai Determinan Kesehatan yang Penting pada Tatanan Rumah Tangga di Kota Bandung
}

\author{
Ardini S Raksanagara ${ }^{1}$, Ahyani Raksanagara ${ }^{2}$, \\ ${ }^{1}$ Departemen Ilmu Kesehatan Masyarakat, Fakultas Kedokteran Universitas Padjadjaran, ${ }^{2}$ Dinas Kesehatan Kota \\ Bandung
}

\begin{abstract}
Abstrak
Program Perilaku Hidup Bersih dan Sehat (PHBS) adalah upaya promosi kesehatan yang bertujuan agar orangorang Indonesia tinggal di lingkungan yang bersih dan sehat. Program PHBS di tatanan rumah tangga memiliki peran yang sangat penting dalam kejadian penyakit menular dan penyakit tidak menular.. Saat ini, penyakit menular atau tidak menular baik di daerah perkotaan maupun kumuh perkotaan di Kota Bandung tetap tinggi. Selain itu berbagai indikator yang terdapat dalam Program PHBS, terdapat faktor lain yang turut berperan yaitu perubahan iklim yang mungkin menjadi faktor risiko untuk terjadinya penyakit. Penelitian ini ditujukan untuk mengetahui hubungan antara pelaksanaan Program Perilaku Hidup Bersih dan Sehat di tatanan rumah tangga dan penyakit akibat dampak perubahan iklim di Kota Bandung. Hasil penelitian menunjukkan bahwa di wilayah Bandung Barat, perilaku hidup bersih dan sehat berhubungan dengan kejadian Diare, Demam Berdarah dan angka bebas larva dalam rumah tangga. Semakin tinggi nilai Perilaku Hidup Bersih dan Sehat, semakin rendah kejadian penyakit diare, demam berdarah dan angka bebas larva. Hasil studi ini dapat digunakan oleh para pembuat kebijakan kesehatan untuk menempatkan PHBS sebagai faktor penentu dan menjadi program utama dalam pengendalian penyakit menular dan mitigasi dampak perubahan iklim terhadap kesehatan masyarakat.
\end{abstract}

Kata kunci : Determinan kesehatan, perubahan iklim, perilaku hidup bersih dan sehat (PHBS)

\section{Clean and Health Living Behavior at Household Setting as an Important Determinant Health in Bandung}

\begin{abstract}
Clean and Healthy Living BehaviorProgram is a health promotion efforts that the Indonesian people are living in a clean and healthy environment. This program is known as PHBS (Perilaku Hidup Bersih dan Sehat) and can be implemented in several setting ie, Health Service Office, Household, Workplace, Public Facilities and School. Clean and Healthy Living BehaviorPrograms at household setting plays an important role in the incidence of infectious diseases and non-communicable diseases. Bandung is the third largest city in Indonesia. Nowadays, infectiousdiseases or non-communicable either in Bandung remains high. One of the causes of the diseases is as a result of 10 indicators contained in the Clean and Healthy Living Behavior. In addition, climate change may be a risk factor for disease. Therefore, this research is needed to determine the relationship between implementing the Clean and Healthy Living Behavior at household setting and disease due tothe impact of climate change in Bandung. The results showed that in West of Bandung, clean and healthy living behavior associated with the incidence of Diarrhea, Dengue Fever and free numbers larvae in household. The higher the value of Clean and Healthy Living Behavior, the lower the incidence of diarrheal diseases, dengue fever and the number of free larvae. The study results can be used by health policy makers to put Clean and Healthy Living Behavior Program $(P H B S)$, as determinant factor, into the main program in infectious disease control and mitigation of the impact of climate change on community health
\end{abstract}

Key words : Clean and healthy behavior, climate change, determinant of health, PHBS

\footnotetext{
Korespondensi :

Dr. Ardini S. Raksanagara, dr., MPH

Departemen Ilmu Kesehatan Masyarakat Fakultas Kedokteran Unpad

Jl. Eijkman No. 38 Bandung

Mobile : 0811237159

Email : araksanagara@yahoo.com
} 


\section{Pendahuluan}

Perubahan iklim yang terjadi saat ini dapat memengaruhi kesehatan masyarakat baik yang tinggal di negara-negara berkembang maupun di negara-negara maju dengan terjadinya berbagai penyakit, terutama penyakit tular vector seperti demam berdarah; selain itu perubahan iklim juga dapat menjadi factor risiko untuk timbulnya Diare, dan Infeksi Saluran Pernafasan Akut (ISPA). ${ }^{1}$ Kondisi tersebut, menurut Hendrik L. Blum, karena kejadian penyakit di masyarakat dipengaruhi oleh empat faktor, yaitu, faktor lingkungan, factor perilaku, faktor pelayanan kesehatan dan faktor genetik. ${ }^{2}$

Terdapat berbagai upaya untuk mencegah penyebaran penyakit menular sebagai akibat dari perubahan iklim. ${ }^{3-6}$ Upaya pencegahan yang paling utama dan merupakan upaya pencegahan primera dalah berbagai kegiatan manusia dan perilaku manusia yang harus dilakukan oleh keluarga sebagai kelompok masyarakat terkecil yang dikenal sebagai Program Perilaku Hidup Bersih dan Sehat (PHBS). Departemen Kesehatan telah mencanangkan PHBS untuk mencapai tujuan MDGs pada 2015. ${ }^{7,8}$ PHBS adalah seperangkat perilaku yang dipraktikkan atas dasar kesadaran sebagai hasil dari pembelajaran, yang membuat seseorang atau keluarga dapat membantu diri mereka sendiri di bidang kesehatan dan berperan aktif dalam program kesehatan masyarakat. PHBS dapat dilakukan berbagai tatanan, yaitu tatanan TempatKerja, Pelayanan Kesehatan, Tempat Umum dan Tatanan Rumah Tangga. Terdapat 10 indikator Program Perilaku Hidup Bersih dan Sehat di tatanan rumah tangga yang harus dilakukan oleh keluarga dan semua anggotanya. Adapun 10 indikator dalam Perilaku Hidup Bersih dan Sehat di tatanan rumah tangga adalah 1) melaksanakan persalinan oleh tenaga kesehatan, 2) ASI eksklusif 3) anak di bawah 5 tahun ditimbang setiap bulan, 4) menggunakan air bersih, 5) mencuci tangan dengan air bersih dan sabun, 6) menggunakan jamban sehat, 7) memberantas jentik nyamuk, 8) makan sayur dan buah setiap hari, 9) melakukan aktivitas fisik setiap hari dan 10) tidak merokok di dalam rumah

Upaya PHBS jika tidak dilakukan oleh masingmasing keluarga dan anggota keluarganya akan menjadi factor risiko untuk timbulnya penyakit, baik infeksi atau penyakit tidak menular. Namun, jika upaya PHBS dilaksanakan dengan baik, maka upaya ini akan menjadi upaya yang efektif untuk mencegah penyakit menular seperti penyakit akibat dampak perubahan iklim. Dapat dikatakan bahwa upaya PHBS dapat menjadi determinan penyakit dan juga pencegahan penyakit.

Kota Bandung adalah daerah perkotaan yang penduduknya meningkat setiap tahun. Berdasarkan Profil Kesehatan Kota Bandung (2012), dan pada saat ini penyakit berbasis lingkungan masih menjadi masalah kesehatan masyarakat. ISPA dan Diare adalah penyakit berbasis lingkungan yang selalu berada di diurutan teratas 10 penyakit yang paling umum di semua pusat pelayanan kesehatan primer di Bandung, ${ }^{1}$ selain itu, kejadian demam berdarah terus meningkat. Berbagai penyakit menular yang terjadi pada masyarakat ini dapat dicegah dengan pelaksanaan berbagai indikator yang terdapat dalam Program PHBS pada tatanan rumah tangga

Pertanyaan dalam penelitian ini adalah bagaimana pelaksanaan Program PHBS pada tatanan rumah tangga di Kota Bandung; bagaimana kejadian penyakit sebagai akibat dari dampak perubahan iklim dan bagaimana hubungan antara pelaksanaan Program PHBS pada tatanan rumah tangga dengan penyakit akibat dampak perubahan iklim

Tujuan dari penelitian ini adalah untuk mengetahui pelaksanaan Program PHBS pada tatanan rumah tangga di Kota Bandung; untuk mengetahui gambaran penyakit akibat dampak perubahan iklim di Kota Bandung; dan untuk mengetahuihubungan antara pelaksanaan Program PHBS pada tatanan rumah tangga dan penyakit akibat dampak perubahan iklim di Kota Bandung

\section{Metode}

Desain penelitian adalah cross-sectional dengan pendekatan retrospektif. Data yang digunakan adalah data sekunder yang berasal dari Profil Kesehatan Kota Bandung 2012; untuk menggambarkan pelaksanaan Program PHBS pada tatanan rumah tangga dan bagaimana hubungannya dengan kejadian Diare, kejadian Demam Berdarah dana ngka bebas larva dalam rumah tangga.

Variabel yang diukur adalah 1) Variabel bebas, yaitu persentase PHBS tatanan rumah tangga Kota Bandung . Data dikumpulkan dari semua pusat pelayanan kesehatan primer (puskesmas) di Bandung yang dilaporkan ke Dinas Kesehatan Kota 2) Variabel tergantung, yaitu Penyakit menular yang disebabkan dampak perubahan iklim (Diare dan Demam Berdarah) serta angka bebas larva dalam rumah tangga.

Data terjadinya penyakit menular didapatkan daripasien yang mencari pengobatan ke puskesmas di Bandung. Kejadian diare dan demam berdarah diukur berdasarkan jumlah pasien yang mendapat pelayanan di puskesmas dan dibandingkan dengan populasi yang ada di Kota Bandung. Angka bebas Larva diukur dengan 
jumlah rumah yang bebas larva dibandingkan dengan jumlah rumah diperiksa.

Data diperoleh dari data seluruh kecamatan di Kota Bandung dan dilaporkan ke Dinas Kesehatan Kota Bandung pada tahun 2012. Wilayah Pelayanan Dinas Kesehatan Kota Bandung dibagi menjadi 4 kategori area dengan titik pusat Dinas Kesehatan Bandung. Metode ststistik yang digunakan adalah korelasi nonparametric karena simpulan ditarik tanpa memperhatikan distribusi populasi. Adapun analisi yang digunakan adalah analisis korelasi angka Spearman dengan perangkat lunak computer telah digunakan untuk menganalisis korelasi antara variable terikat dan variabel bebas

\section{Hasil}

Jumlah lokasi penelitian adalah 30 kecamatan yang dibagi menjadi 4 kategori daerah penelitian. Kecamatan yang berada dalam wilayah kerja Dinas Kesehatan Kota Bandung dibagi menjadi Wilayah Utara, Selatan, Barat danTimur. Dari setiap kecamatan diperoleh hasil pengukuran mengenai PHBS tatanan rumah tangga berdasarkan pencapaian 10 indikator perilaku hidup bersih dan sehat di rumah tangga yang dilakukan oleh petugas kesehatan di puskesmas.

Data kejadian diare diambil dari Profil Kesehatan Kota Bandung tahun 2012. Data ini diperoleh dari hasil pencatatan dan pelaporan dari puskesmas ke Dinas Kesehatan Kota. Kejadian diare dan demam berdarah diukur dari jumlah pasien yang mendapatkan pengobatan di Puskesmas dibagi dengan jumlah penduduk. Angka bebas larva diukur dari penilaian petugas kesehatan untuk memeriksa apakah ada atau tidak ada larva di rumah penduduk. Angka bebas larva diperoleh dari penilaian rumah bebas larva dibagi dengan jumlah rumah diperiksa.

Berdasarkan evaluasi di 30 kecamatan yang berada di Kota Bandung ditemukan bahwa indikator rata-rata Perilaku Hidup Bersih dan Sehat (PHBS) di tatanan rumah tangga adalah 65,57\% (kisaran 12,60-92,84\%;. SD $=20,33$ rata-rata kejadian diare adalah 3,15\% (kisaran $1,07 \%-8,28, \quad$ SD $=1,58)$, kejadian demam berdarah adalah $0,22 \%$ (kisaran $0,10-0,43 \%$, SD $=0,08)$ dan jumlah rumah bebas larva mencapai $93,21 \%$ (kisaran $81,44 \%-100, \quad S D=3,82$ ). Hasil penelitian ini dapat dilihat pada Tabel 1.

Tabel 1. Hasil Analisis Univariat

\begin{tabular}{lcccc}
\hline & PHBS & Diare & Demam Berdarah & Angka Bebas Larva \\
\hline Median & 65,57 & 3,15 & 0,22 & 93,21 \\
Standard Deviation & 20,33 & 1,58 & 0,008 & 3,82 \\
Minimum & 12,60 & 1,07 & 0,1 & 81,44 \\
& & & & 100 \\
Maximun & 92,84 & 8,38 & 0,43 & \\
& & & &
\end{tabular}

Berdasarkan hasil penelitian yang dilakukan di 4 kategori kecamatan di Kota Bandung, diketahui bahwa di wilayah barat Kota Bandung , ada hubungan antara perilaku hidup bersih dan sehat, kejadian diare, kejadian demam berdarah dan angka bebas larva. Berdasarkan perhitungan koefisien korelasi diperoleh angka PHBS terkait dengan kejadian diare $(r=-0,70)$ dan angka bebas larva $(r=-0,60)$ sangat kuat, serta terkait dengan insiden berdarah $(r=-0.20)$ sangat lemah.

Berdasarkan perhitungan komputer dari koefisien korelasi, diduga bahwa perilaku hidup bersih dan sehat di tatanan rumah tangga dikaitkan dengan kejadian diare dengan $\mathrm{r}=$ $-0,70$; dan angka bebas larva dengan $r=-0,60$ ini menunjukkan bahwa perilaku hidup bersih dan sehat berhubungan negatif dengan kejadian diare dan angka bebas larva sangat kuat. Jika angka 
yang diperoleh perilaku hidup bersih dan sehat di tatanan rumah tangga menjadi lebih baik, maka semakin rendah kejadian diare dan angka bebas larva. Untuk hubungan antara PHBS dan kejadian demamberdarah, berdasarkan perhitungan statistik diperoleh nilai $\mathrm{r}=-0,2$, yang berarti hubungan sangat lemah atau bahkan tidak berhubungan. Hasil analisis dapat dilihat pada Tabel 2.

Tabel 2. Hasil Analisis Non Parametrik

\begin{tabular}{lc}
\hline Variabel & $\begin{array}{c}\text { PHBS } \\
(\mathbf{r})\end{array}$ \\
\hline Diare & $-0,70$ \\
Demam Berdarah & $-0,60$ \\
Angka Bebas Larva & $-0,20$ \\
\hline
\end{tabular}

\section{Pembahasan}

Program Perilaku Hidup Bersih dan Sehat (PHBS) pada tatanan rumah tangga telah ditetapkan untuk dilaksanakan pada beberapa dekade yang lalu, dan penyakit menular yang ditemukan di Indonesia masih merupakan masalah utama. ${ }^{7,8}$ Pada saat ini, masyarakat di dunia saat ini sedang menghadapi masalah global yaitu terjadinya dampak perubahan iklim terhadap kesehatan. ${ }^{1,4}$ Studi ini meneliti bagaimana hubungan antara Program PHBS pada tatanan rumah tangga dengan penyakit menular sebagai akibat dari dampak perubahan iklim. Berdasarkan buku pegangan dari Departemen Kesehatan (2009) dan Dinas Provinsi Jawa Barat Kesehatan (2009), ${ }^{7,8}$ Program PHBS pada tatanan di Rumah Tangga adalah upaya untuk memberdayakan anggota rumah tangga untuk mengetahui, mau dan mampu mempraktikkan perilaku hidup bersih sehat dan berpartisipasi aktif dalam gerakan kesehatan masyarakat.

Terdapat 10 indikator dalam Bersih dan Kesehatan Hidup Program Perilaku dalam pengaturan rumah tangga. Ada beberapa indikator. dari 10, yang berkaitan dengan penyakit menular yang disebabkan oleh perubahan iklim 1) Menggunakan air bersih 2) Cuci tangan dengan sabun dan air bersih 3) Menggunakan toilet yang sehat dan 4) Menghilangkan larva di rumah sekali seminggu. ${ }^{8}$ Faktor-faktor ini merupakan faktor risiko, jadi jika indikator ini tidak dilaksanakan di rumah tangga maka akan berdampak pada timbulnya penyakit menular. Menurut Hendrik L. Blum Teori, kejadian penyakit di masyarakat dipengaruhi oleh empat faktor, yaitu, faktor lingkungan, faktor perilaku, faktor pelayanan kesehatan dan faktor genetik.
Dari semua 4 faktor ini, efek yang paling berperan sebagai determinan penyakit menular adalah lingkungan dan perilaku. Untuk terjadinya demam berdarah, lingkungan tang bersih dan sehat 1 dengan membersihkan larva setiap minggu akan mengurangi risiko terjadinya demam berdarah karena mengurangi jumlah vektor penyakit. Untuk kejadian diare, dengan selalu menggunakan air bersih dan toilet yang memenuhi syarat serta mencuci tangan akan mengurangi risiko diare. Dapat disimpulkan bahwa Perilaku Hidup Bersih dan Sehat Perilaku dalam tatanan rumah tangga merupakan determinan kesehatan

Analisis hasil ditunjukkan dengan adanya hubungan negatif, semakin tinggi indikator Program Perilaku Hidup Bersih dan Sehat yang dilaksanakan pada tatanan rumah tangga, maka kejadian Diare dan Demam Berdarah akan menurun. Hal ini dapat dijelaskan bahwa kejadian penyakit menular akan menurun, karena anggota rumah tangga telah menerapkan berbagai kegiatan untuk mencegah penyakit, seperti penggunaan air bersih, mencuci tangan dengan sabun dan memeriksa serta membersihkan larva seminggu sekali yang menjadi faktor risiko untuk tingkat terjadinya diare dan demam berdarah,

Hasil penelitian menunjukkan bahwa di Bandung Barat perilaku hidup bersih dan sehat berhubungan dengan kejadian Diare, Demam dengue dan angka bebas larva dalam rumah tangga. Dapat disimpulkan bahwa Perilaku Hidup Bersih dan Sehat di tatanan rumah tangga berhubungan dengan kejadian penyakit diare, demam berdarah dan angka bebas larva. Semakin tinggi nilai Hidup Bersih dan Sehat Perilaku ditatanan rumah tangga, semakin rendah kejadian penyakit diare, demam berdarah dan angka bebas larva

Hasil penelitian ini dapat digunakan oleh para pembuat kebijakan kesehatan untuk menentukan bahwa Program Perilaku Hidup Bersih dan Sehat adalah sebagai faktor penentu/determinan dan dimasukkan ke dalam program utama dalam pengendalian penyakit menular dan mitigasi dampak perubahan iklim terhadap kesehatan masyarakat Keterbatasan penelitian ini adalah bahwa data tersebut hanya menganalisis data dari 1 tahun (2012). Jika data yang diambil dari beberapa tahun, maka analisis akan lebih baik karena dapat diketahui kecenderungan Prilaku Hidup Bersih dan Sehat di tatanan rumah tangga dan kejadian penyakit menular akibat dampak perubahan iklim. Selain itu, untuk kategori wilayah kecamatan, kurang memperhatikan batas-batas wilayah kerja dan tidak ada ketentuan standar, dan hanya ditentukan oleh geografis 


\section{Daftar Pustaka}

1. Samet, JM. Adapting to Climate Change Public Health. Adaptation-An Initiative of the Climate Policy Program. RFF. June, 2009

2. Detels R, Breslow L, editors. Oxford textbook of public health. 4th ed. New York: Oxford University Press; 2002.

3. Kim-Farley RJ. Global strategies for control of communicable diseases. In: Detels et al. (eds). Oxford Textbook of Public Health. Vol. 3. NewYork: Oxford University Press, 2002, pp. 1839-59

4. Omenn, G.S and Faustman, E.M (2002) Risk Assessment and Risk Management in Oxford Textbook of Public Health, 4th ed., Oxford university Press, 2002, pp. $1083-1104$
5. WHO. (2002) The World Health Report 2002: Reducing Risk, Promoting Healthy Life. Chapter 2: Defining and Assessing Risks to Health. Geneva; WHO, pp. $7-26$

6. Witoelar, R. IsuPerubahanIklim: Pencetus Perubahan Pengelolaan Lingkungan Hidup Ke Arah yang Lebih Baik. Dokumen Sekretariat Negara RI. Diunduh dari www. pdfebook.com pada tanggal 2 Mei 2014

7. Departemen Kesehatan (2009), Program Perilaku Hidup Bersih dan Sehat, Jakarta. Dinas Kesehatan Kota Bandung (2012), Profil Kesehatan Kota Bandung.

8. Dinas Kesehatan Propinsi Jawa Barat (2009), Perilaku Hidup Bersih dan Sehat, Bandung. 